\title{
ТРУДНОСТИ ДИФФЕРЕНЦИАЛЬНОЙ ДИАГНОСТИКИ РАННЕГО СЕРОНЕГАТИВНОГО СПОНДИЛОАРТРИТА В УСЛОВИЯХ ЭПИДЕМИЧНОЙ ЗОНЫ ПО БРУЦЕЛЛЕЗУ
}

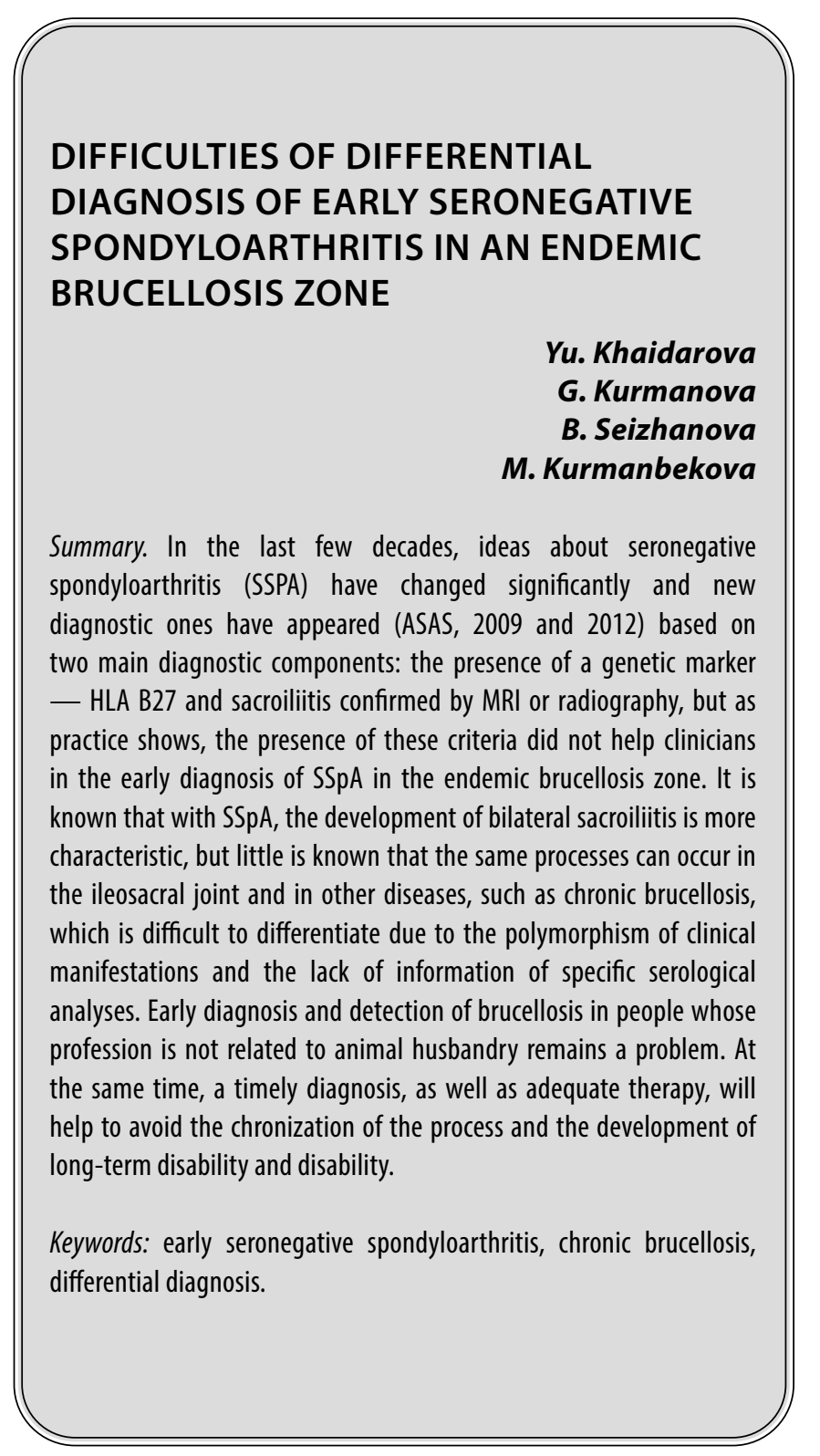

5 руцеллез (лихорадка мальтийская, средиземноморская, гибралтарская, кипрская, ундулирующая, тифомалярийная, болезнь Банга) - зоонозная инфекционная болезнь, вызываемая бактериями, объединенными под общим названием Brucella, с высокой потенциальной возможностью перехода в хроническую форму, характеризующейся системным поражением органов и систем с преимущественным
Хайдарова Юлдуз Мадихановна

PhD докторант, Казахский Национальный Университет имени Аль-Фараби; врач - ревматолог, Городской Ревматологический чентр г. Алматы duzka_0801@mail.ru

Курманова Гаухар Медеубаевна Д.м.н., профессор, Казахский Начиональный Университет имени Аль-Фараби gkurman@mail.ru

Сейжанова Багжан Бериковна

PhD докторант, врач - ревматолог, Казахский Национальный Университет имени Аль-Фараби ms.bagzhan@mail.ru

Курманбекова Молдир Бихитовна Врач-кардиолог, Клиника «SEMA» moldir_bahutkuzu@mail.ru

Аннотация. В последние несколько десятилетий существенно изменились представления о серонегативных спондилоартритах (ССп) и появились новые диагностические (ASAS, 2009 и 2012), основанные на двух основных диагностических составляющих: наличии генетического маркера - HLA B27 и сакроилеита, подтвержденного с помощью MPТ или рентгенографии, но как показывает практика наличие и этих критериев не помогло клиницистам в ранней диагностике ССпА в эндемичной зоне по бруцеллезу. Известно, что при ССпА более характерно развития двухстороннего сакроилеита, но мало известно, что такие же процессы могут возникать в илеосакральном сочленении и в других заболеваниях, таких как хронический бруцеллез, который тяжело дифференцировать из-за полиморфизма клинических проявлении и малоинформативности специфических серологических анализов. Остается проблемой ранняя диагностика и выявление бруцеллеза у людей, профессия которых не связан животноводством. В то же время своевременно поставленный диагноз, а также адекватная терапия позволят избежать хронизацию процесса и развитию длительной потери трудоспособности и инвалидности.

Ключевые слова: ранний серонегативный спондилоартрит, хронический бруцеллез, дифференциальная диагностика.

поражением опорно-двигательного аппарата, нервной и половой систем.

Заболеваемость бруцеллезом людей в Республике Казахстан превышает средний показатель заболеваемости в целом по СНГ в 6-8 раз [1]. Социально-экономическая значимость проблемы бруцеллеза определяется особенностями течения данной инфекции с частым 
развитием хронических форм у трудоспособного население страны с различными резидуальными осложнениями, приводящей к инвалидности.

Хронический бруцеллез - зоонозное инфекционно-аллергическое заболевание, вызываемое бактериями рода Brucella, протекающее свыше шести месяцев, характеризуется выраженным полиморфизмом клинических проявлений с преимущественным поражением опорно-двигательной, нервной, мочеполовой и др. систем, склонностью к рецидивирующему течению [14]. Различают 2 формы хронического бруцеллеза согласно клинической классификация (Н.Д. Беклемишев (1957), дополненной К.Б. Курмановой, А.К. Дуйсеновой (2002): первично-хронический бруцеллез (отсутствие острой фазы при хроническом течении болезни) и вторично-хронический бруцеллез (свыше 6 месяцев от дебюта острого начала заболевания). Хронический бруцеллѐз характеризуются вариабельностью клинических проявлений и рецидивирующим течением.

В условиях Казахстана, который является эпидемичной зоной по бруцеллезу, хроническая форма инфекции протекает с симптомами, аналогичными таковым при серонегативных спондилоартропатиях: боли в спине, сакроилеит, периферического несимметричного артрита и\или артралгией, и в около $40 \%$ случаях с позитивностью по гену HLA -B27, появляются множественные трудности в дифференциальной диагностике в ранней стадии заболевания [2]. Одним из основных диагностически значимых проявлений ССпА является боль, которая возникает постепенно, локализуется в области ягодиц, может носить перемежающий характер и иррадировать в проксимальные отделы бедер. Именно так проявляется сакроилеит и при хроническом бруцеллезе. При ССпА также и при хроническом бруцеллёзе, наблюдаются сходные симптомы: боли в спине, одно и двухсторонний сакроилеит, вплоть до анкилозов, несимметричный моно- и полиартриты, явления остеопороза и другие внесуставные симптомы как поражение сердца и глаз. Отмечаются идентичные лабораторные данные - анемия, ускоренная СОЭ, диспротеинемия, негативность по РФ, обнаружение гена HLA B27, но лечение данных пациентов в корне отличается от друг от друга, а диагностическая ошибка приведет к неверной лечебной тактике, которая при применении биологической терапии может стать причиной трагичного исхода.

Своевременная диагностика хронического бруцеллеза является большой проблемой ввиду нескольких причин. Для хронического бруцеллеза характерно полиморфизм клинических проявлении, большой степени очаговой симптоматики, которые могут имитировать различные заболевания, которые требуют огромные усилия и времени для исключение других состоянии. Скудность проявлении интоксикационного синдрома и преобладание очаговой симптоматики над симптомами интоксикации затрудняет задачу врача увидеть инфекционную патологию и своевременно отреагировать на заражение бруцеллезом.

\section{ТруАности АИфференшиальной АИагностИкИ с КАИнической точкИ зрения}

Хронический бруцеллез можно рассматривать как системное инфекционное заболевания связи с очаговыми поражениями со стороны различных органов и систем, так как бруцелла не имеет тропность к определенным клеткам организма и может поражать все клетки организма. Формирование очаговых и системных поражений определяется ответной воспалительной реакцией организма на циркулирующий возбудитель, местной воспалительной реакцией, аллергической перестройкой организма на циркулирующий эндотоксин и возможными аутоиммунными реакциями.

Хроническое течение бруцеллёза патоморфологически характеризуются образованием инфекционно-аллергических гранулём, развитием очаговых экссудативно-пролиферативных процессов в период обострений болезни и последующими рубцовыми и склеротическими изменениями в органах и тканях. В патологический процесс при хроническом бруцеллёзе могут вовлекаться любые органы и в любых сочетаниях [1].

Дифференциально-диагностические трудности между СпА и хроническим бруцеллезом возникает изза схожести поражение костно-суставной системы, вовлечением в процесс патологии глаз (анкилозирующий спондилит) и половых органов (реактивные артриты).

Наиболее часто очаговые поражения хронического бруцеллеза наблюдаются со стороны опорно-двигательного аппарата. Костно-суставные осложнения, возможно, обусловлены генетической предрасположенностью. Получены данные об ассоциации бруцеллезных артритов и сакроилеита с антигеном HLA-B39 [14].

В 1992 году было доказано (Salvarani $C$ et all, 57 пациентов), что наличие антигенов HLA-B39 и HLA-DR4 являются лучшими предикторами воспалительного заболевания шейного отдела позвоночника у пациентов с псориатическим артритом [7]. В 1995 году в Японии было проведено исследования - серологическое HLA-типирования 1 класса у пациентов с анкилизирующий спондилитом (AC) (48), ювенильным ревматоид- 
ным артритом (ЮРА) (66) и контрольной группы (210), которое доказал повышение частоты HLA B39 у HLA B27 негативных пациентов с АС и у пациентов с суставной формой ЮРА, который характеризуется высокой заболеваемости хроническим увеитом, асимметричным артритом, большой степени развитием сакроилеита и имеет схожие клинические проявления с СпА $[5,6]$. Основываясь патогенетический принцип, суставной синдром при хроническом бруцеллезе представлен в следующих формах [12]:

1. Артралгии нервно-вегетативного происхождения, чаще в крупных суставах и по ходу позвоночнике.

2. Реактивные артриты.

3. Инфекционно-метастатические артриты поражения костей и суставов;

4. Системные поражения аутоиммунного генеза.

Артралгия встречается у 42,2-86\% больных с диагнозом острый и обострения хронических форм бруцеллеза. Для пациентов с хроническим бруцеллезом характерно полиартронейромиалгии и оссалгии - это когда одновременно болезненные ощущения возникают суставах, костях, мышцах и нервных окончаниях и за частую пациенты с хроническим бруцеллезом не могут локализовать боль и им кажется болит везде и всегда. И.Л. Касаткина и Н.Д. Беклемишев (1976) считают, что в основе патогенеза таких состоянии лежат нарушения в вегето-сосудистой регуляции (сосудистые спазмы) [12]. Реактивные артриты проявляются в виде олигоартрита и/или полиартрита, чаще поражается мелкие суставы кистей рук, иногда симметричный полиартрит, что затрудняет дифференциальную диагностику с ревматоидным артритом, особенно у РФ позитивных пациентов. Особенность бруцеллезного артрита является летучесть поражения, доброкачественность течения и обратимость патологического процесса при адекватной терапии. Рентгенологические изменения в суставах при этом не определяются. Инфекционно-метастатический артрит протекает более тяжело, чаще в виде моноартрита, с вовлечением в патологический процесс крупных суставов, чаще коленных суставов с образованием вторичного остеоартроза [14].

Встречаемость боли в спине при бруцеллезе колеблется в зависимости от вида бруцеллеза и от вида поражение позвоночника: спондилиты 10,2\%, спондилоартрозы - 12,2\%, спондилодисциты - 5,8\%, спондилез - 8,6\%, остеохондроз-37,6\%, хотя наиболее частым и характерным для бруцеллёза является поражение крестцово-подвздошных сочленений - сакроилеит, который не привлекают внимания врачей в связи с наличием сопутствующих симптомов со стороны мышц, крестцовых и седалищных нервов и сакраилеит при бруцеллезе чаще диагностируется как неврит седалищ- ного нерва или остеохондроз пояснично-крестцового отдела позвоночника с корешковым синдромом [1]. Сакроилеит при бруцеллезе бывает одно- или двухсторонним и проявляется сильными болями в области крестца, усиливающиеся при движении, особенно при ходьбе и наклоне туловища вперёд; в тяжёлых случаях больные неподвижно лежат на спине, боясь пошевелиться, чтобы не вызвать усиления болей [1]. Одним из вариантов поражения позвоночника при бруцеллезе может быть развитие остеохондрита или поражение межпозвонковых дисков с последующей деструкцией субхондрального отдела кости, быстрым развитием мощных остеофитов с обызвествлением продольных связок на уровне пораженного диска. Возможно развитие спондилита или спондилоартрита чаще в поясничном отделе позвоночника и реже в шейном отделе, которые клинически проявляются сильными болями при надавливании на остистые отростки позвонков. К типичным при бруцеллезе является поражение акромио-ключичное сочленения [14].

Когда речь идет схожести клинических проявлении и трудности дифференциальной диагностики СпА и хронического бруцеллеза нельзя забывать о внеаксиальные проявления СпА, такой как поражения глаз при АС и реактивном артрите, так как при бруцеллезной инфекции также может развиться разные виды офтальмопатии, что доказывают нижеописанные исследования. В 2006-2008 гг в Перу было проведено проспективное исследование, где оценивалось данные пациентов с января 1980 года по декабрь 2005 года, которым был поставлен диагноз бруцеллез с поражением глаз. Диагноз был поставлен на основании клинических данных, а также агглютинаций и / или положительных результатов посева на Brucella melitensis. 3а 26 лет было обследовано 1551 пациентов с бруцеллезом, среди которых было обнаружено 52 пациента с бруцеллезным поражением глаз. Выявлено, что у 7 (0,7\%) из 965 пациентов с острым бруцеллезом и у 45 (7,9\%) из 570 пациентов с хроническим бруцеллезом было диагностировано бруцеллезное поражения глаз ( $P<0,001$. Наиболее частой патологией глаз был увеит, который был обнаружен у $43(82,7 \%)$ из 52 пациентов с глазным бруцеллезом. Задний увеит верифицирован у 45,6\% пациентов (21) и у 9 пациентов был выявлен панувеит, из них у 8 пациента развилась слепота [11].

Обсуждая данную проблему, хотелось бы продемонстрировать результаты другого интересного исследования, которые проводили офтальмологи во главе профессора Павлюченко А.К. (79 пациентов с АС, Украина), которые выявили поражение глаз на разных этапах течения AC у $29 \%$ от общего числа обследованных больных в виде увеита, склерита, кератита, катаракты, глаукомы и конъюнктивита в соотношении 7: 5: 2: 2: 1, 
причем с темпами прогрессирования артрита и с поражением отдельных суставов тесно связаны отдельные варианты офтальмопатии, а на выраженность их влияют степень активности заболевания, наличие тендовагинитов и энтезопатий, тяжесть спондилопатии, остеопороз и костно-деструктивные изменения артикулярного аппарата. Во время исследования доказана клинически значимая связь с развитием офтальмопатий с поражением грудино-ключичных сочленений (увеит, кератит, глаукома, катаракта) и пястно-фаланговых и локтевых сочленений (увеит, кератит, глаукома). Авторы рекомендуют оценивать поражения грудино-ключичных сочленений как фактора риска развития офтальмопатий, наличие узурации в костях - как фактора риска тяжелого течения увеита, вовлечение в процесс лучезапятных и локтевых суставов - как предиктора периферического варианта увеита [10]

ТруАности Аифференциальной

АИагностики ССпА и хрОНИческого

бручемлеза (^абораторно)

Методы, используемые для лаблраторной диагностики бруцеллезной инфекции можно разделить на 3 группы:

1. Выявление возбудителя заболевания и его растворимых антигенов: выделение культуры Brucella Spp., полимеразная цепная реакция (ПЦР)

2. Определение специфических антител: пластинчатая реакция агглютинации (реакция Хеддльсона), реакция агглютинации в пробирках (реакция Райта), антиглобулиновая проба Кумбса, реакция пассивной гемагглютинации (РПГА), иммуноферментный анализ (ИФА)

3. Выявление сенсибилизации организма к бруцеллезным антигенам: кожно-аллергическая проба Бюрне.

Согласно исследованиям, результаты, используемые для постановки диагноза «бруцеллез», серологических исследований оказались ненадежными. Результат реакций Райта у пациентов с первично-хроническим бруцеллезом 41,5\% и вторично-хроническим бруцеллезом 32,7\% случаях оказались отрицательными, тогда как результаты реакции Хаддлсона 11,1\% случаях стали отрицательными и 4,5\% сомнительным при первично-хроническом бруцеллезе, а при вторично- хроническом бруцеллезе 6,5\% и 2,7\% соответственно. Следует помнить, что при хроническом бруцеллезе имеет место подавление антителообразования и ценность серологических методов снижается. Касательно результатов теста с Роз-бенгал антигеном, обладающий большой чувствительностью, способностью в короткие сроки после заражения выявлять специфические бруцеллёзные антитела, больше половины пациентов $(51,3 \%)$ с первично-хроническим бруцеллезом и чуть меньше одну треть пациентов $(28,6 \%)$ с вторично-хроническим бруцеллезом оказались отрицательными. Результаты ИФА на определения бруцеллезных антител были положительными только у 40-50\% больных с хроническим бруцеллезом. ИФА на бруцеллез чаще бывает отрицательным, так как иммунный ответ при бруцеллезе происходит по Т клеточного типу, а продуцированные антитела к бруцеллезу не играют защитную роль и выступают как «свидетель иммунитета», а также имеет место быть «феномен ускользания» от иммунной системы связи особенностями строения бактерии и реакции иммунитета на наличие данного антигена. Только около 2,4-4\% пациентов с хроническим бруцеллезом были выделены гемакультура бруцеллы, так как при хронических формах бруцеллеза наблюдается скудность проявлении интоксикационного синдрома, нередко отсутствует лихорадочный синдром.

В 2006 году Каральник Б.В. и другие изучили эффективность различных методов диагностики бруцеллеза (115 пациентов): реакции Хаддлсона, Райта, РозБенгал-тест, ИФА с разработанной lgG-тест системой и тест АСЛ (антигенсвязывающие лимфоциты). Анализ показал, что реакция Райта оказалась достоверно $(\mathrm{P}=0,031)$ менее чувствительной, в 1,3 раза, чем реакция Хаддлсона, и достоверно $(\mathrm{P}=0,013)$ менее чувствительной, в 1,4 раза, чем РозБенгал тест. Существенных различий между чувствительностью реакции Хаддлсона и РозБенгал теста выявить не удалось $(\mathrm{P}=0,108)$. Другими словами, у 75\% пациентов с бруцеллезом ИФА для определения IgG антител к ЛПС бруцелл был положительным, у 51,7\% пациентов с хроническим бруцеллезом реакция Хадлсона был положительным, тогда как реакция Райта был позитивным только 39,3\% пациентов. На этом исследовании выявили, что определение антигенсвязывающих лимфоцитов при диагностике бруцеллеза является более чувствительным тестом, чем тесты определения антител и он позволяет вести ранний контроль эффективности лечения бруцеллеза, так как у переболевших бруцеллезом пациентов результат АСЛ стал отрицательным 9,6 раз чаще чем у пациентов в активной фазе болезни [4].

Учитывая трудности своевременной диагностики хронического бруцеллеза для облегчения верификации диагноза необходимо использовать стандартное определения случая хронического бруцеллеза. Трудность диагностики этих двух состояния еще усугубляется у HLA B27 позитивного пациента. В 1978 году Hodinka et. al. сообщили о положительной связи между наличием антигена HLA-B27 и спондилоартритом при хроническом бруцеллезе, вызванном B.abortus. 44\% из 27 пациентов с бруцеллезным спондилоартритом имели 
HLA B27 позитивный статус. [8], но исследования, проводимое в Турции (78 пациентов с хронический бруцеллезом и 100 человек контрольная группа, 2003 год) показала статистически незначимую связь между костно-суставными проявлениями бруцеллеза с антигеном HLA-B27 [9]

\section{СтанАартное опрелеления случаев хронического брушемлеза}

Известно, что бруцеллез является особо опасной инфекцией (ООИ), так как возбудитель инфекции отличаются высокой вирулентностью, устойчивостью их к неспецифическим факторам защиты организма; способность длительно (годами) выживать и даже размножаться внутри иммунокомпетентных клеток (макрофагов); ничтожно малая защитная роль противобруцеллёзных антител. В таких случаях разрабатываются стандартное определение случая (СОС) ООИ, которое позволяет своевременно поставить диагноз, начать лечение и провести комплекс эпидмероприятий для предотвращения распространения инфекции.

В случае ООИ стандартное определение случая включает:

- подозрение на случай: наиболее типичные клинические проявления заболевания, охватывающие до 95\% всех случаев;

- вероятный случай: наиболее типичный эпиданамнез;

- подтвержденный случай: лабораторно подтвержденный случай.

Для бруцеллезной инфекции отдельно разработаны стандартное определение случая для острого, подострого и хронического форм бруцеллеза. Ниже описаны СОС для хронической формы бруцеллеза (таблица 1).

Медицинский работник, выявивший больного острым/подострым бруцеллезом и первично-хроническим бруцеллезом (первичное и повторное заболевание) или подозрительного на него, подает экстренное извещение (ф. 58/y) [13]. Данный СОС для хронических форм бруцеллеза помогает для верификации диагноза, но учитывая полиморфизм очаговых клинических проявлении на фоне ненадежности лабораторных анализов появление трудностей своевременной диагностики и лечения, приводящие к различным видам осложнений является неизбежным.

\section{Зак^ючение}

Пациенты со схожими симптомами раннего СпА и хронического бруцеллеза требуют проведения дифференциальной диагностики во всех случаях волноо- бразного лихорадочного синдрома с эпизодами озноба с очаговыми проявлениями хронического бруцеллеза, такие как сакроилеит, артрит, боль в спине, воспаление в мягких тканях (мышцы, связочный аппарат), поражение глаз и другие не патогномоничных очаговых проявлениях болезни. Нынешнее время в практике терапевта и в частности ревматолога участились случае трудности дифференциальной диагностики раннего ССпА и хронических форм бруцеллеза, особенно когда у пациента с хроническим бруцеллезом нет острого периода инфекции с яркими симптомам и интоксикации, лихорадочного синдрома и клинические проявления стертые, имитируя различные другие заболевания, сопровождающиеся суставным, нейромышечным, астено-вегетативным синдромами на фоне волнообразной субфебрильной лихорадки. Важно помнить, что полная демонстрация клинических симптомов в дебюте болезни может отсутствовать и часто требуются месяцы динамического наблюдения за пациентами для установления типичных проявлений классического ССпА и хронического бруцеллеза. Необходим тщательный разбор каждого клинического случая, так как в реальной практике и ревматолога, и терапевта и инфекциониста могут быть данные ошибки, которые могут закончится крайне печально с развитием устойчивой потери трудоспособности вплоть до летального исхода. Другими причинами развития декомпенсации являются супер- и реинфекция в эндемичных зонах, низкая обращаемость населения за медицинской помощью, плохая организация диспансеризации, отсутствие медицинской реабилитации. Для облегчение дифференциальной диагностики между этими социально значимой патологии необходимо усилить осведомленность о хроническом бруцеллезе среди врачей, кому обычно пациенты обращаются с различными жалобами, чаще всего это врачи общего профиля, ревматологи, невропатологи и другие в зависимости от преобладания очаговой симптоматики. Не мало важно усилить осведомленность врачей офтальмологов о наличии офтальмопатии бруцеллезной этиологии, приводящий к серьезным необратимым осложнениям, которые требуют немедленное реагирования врача в целях предотвращения слепоты в результате серьезного повреждения глаз. Исход и прогноз зависит от своевременной диагностики и корректного подбора лечение заболевания. Необходимо знать, что наличие одного заболевания не исключает присоединения другого: у одного пациента может развиться и ССпА и хронический бруцеллез, при этом пациенты четко отличают изменения характера и интенсивность боли, присоединения новых ранее отсутствующих симптомов, при этом субъективные жалобы пациента зачастую не совпадает с объективными данными и процесс вовлечен центральная и вегетативная нервная система с широким полиморфизмом клинических проявлении. 


\section{Таблица 1}

Подозрение на случай: заболевание более 6 месяцев с лихорадкой или без волнообразного течения и как минимум 2 из нижеперечисленных проявлений:

Общие симптомы

Полиартронейромиалгии, оссалгии (НЦД, дермографизм, нарушения трофики кожи и т.д.)

Гипергидроз ладоней и стоп и/или потливость

Лимфаденопатия

Гепато- и/или

спленомегалия
Вегетативные нарушения

и/или любые очаговые проявления:

Очаговое поражение суставов и околосуставных тканей - у 70\% больных (артриты, перии параартрит, сакроилеит, бурситы, тендовагиниты, спондилит, спондилоартрит, спондилодисцит, артроз, остеохондроз, также остеомиелиты.

Поражение нервной системы - у 100\% больных (ЦНС — менингит, энцефалит, миелит,

диэнцефальный синдром, синдром внутричерепной гипертензии; Периферичексой нервной системы - невриты, плекситы, ганглиолиты, солярит, корешковый синдром и пр.; Вегетативной нервной системы- астено-невротический синдром, потливость вегетативного генеза, синдром раздраженной кишки и пр.; психобруцеллез)

Поражения сердечно-сосудистая система - 10-40\% больных (миокардиты, перикардит, коронарит, эндокардит, миокардиодистрофия; флебиты и тромбофлебиты)

Поражения половых органов (орхит, орхоэпидидимит; дисменорея, невынашивание беременности, бесплодие, ЗВП - задержка внутриутробного развития плода).

Нефрит, редко - гломерулонефрит

Эмоциональная

лабильность, астено-

невротический синдром,

депрессия

Нарушения памяти, сна, головные боли, головокружения, шум в ушах, синкопальные состояния
Увеиты, иридоциклиты

Васкулиты (иммунокомплексные)

Очень редко - пневмония, гепатит, гастрит

Вероятный случай: когда у пациента есть симптомы подозрения случая и положительный эпидемического анамнез. Эпидемиологические критерии возможного инфицирования бруцеллезом:

- Профессиональные группы риска: работники животноводческих хозяйств, мясо- и молококомбинатов и других предприятий по переработке продуктов и сырья животного происхождения, убойных пунктов, пунктов стрижки, купки овец, чабаны, пастухи, доярки, зооветспециалисты, персонал лабораторий, работающих с вирулентными культурами;

- У Употребление пищевых продуктов, полученных от зараженных животных: сырое молоко, молочные продукты, термически плохо обработанное мясо от больных животных. Следует помнить, что заражение могло произойти много месяцев и лет назад. В таких случаях мы можем интерпретировать как «Реинфекция».

Подтверждение диагноза: клинические проявления, подтвержденные лабораторными тестами.

- Реакция Хадлсона положительная (+++), резко положительная (++++); Реакция Райта титр 1/100 и выше;

- ИФА положительная, положительный результат РПГА, реакции Кумбса, РСК (реакция связывания комплимента), АСЛ (диагностическая ценность АСЛ при де- и субкомпенсации - 70-80\%, при компенсации - 17\%)

- Положительная проба Бюрне - следует помнить, что реакций может быть не только локальной (в месте введения аллергена), но и очаговой (реагирует пораженный орган) и/или системной (лихорадка, недомогание и т.п.)

- Положительный результат ПЦР (сыворотка крови - диагностическая ценность менее 30\%, форменные элементы крови, костный мозг, содержимое бурс, биоптат лимфоузлов и т.д.- диагностическая ценность выше)

- Положительный результат бактериологического исследования (кровь - 4-17\% при условии правильного забора и транспортировки к транспортной среде; другой биоматериал). 


\section{ЛИТЕРАТУРА}

1. Курманова К.Б., Дуйсенова А.К. Бруцеллез. Клинические аспекты, Алматы, 2002 г.- 252 с.

2. МАМУТОВА А.Е. «Особенности течения хронического бруцеллеза в условиях хронической интоксикации солями тяжелых металлов и лечение», диссертация на соискание ученой степени кандидата медицинских наук, 2009 год

3. Шостак Н.А., Правдюк Н.Г., Абельдяев Д.В.«Серонегативные спондилоартропатии - совершенствование подходов к ранней диагностике и лечению», «РМЖ» № 6 от 05.03.2013 г. стр.332:

4. Karalnik B.V., Denisova T.G., Zhunusova G.B., Fedosov S.A., Zhankin A.A., Ospanov K.S., Mizanbaieva S.U. Efficiency of different techniques for antibody determination and testing of antigen-binding lymphocytes in diagnostics of brucellosis. Medical Immunology (Russia). 2006;8(4):567-572. (In Russ.) https:// doi.org/10.15789/1563-0625-2006-4-567-572

5. Yamaguchi A, Tsuchiya N, Mitsui H, Shiota M, Ogawa A, Tokunaga K, Yoshinoya S, Juji T, Ito K. Association of HLA-B39 with HLA-B27-negative ankylosing spondylitis and pauciarticular juvenile rheumatoid arthritis in Japanese patients. Evidence for a role of the peptide-anchoring B pocket. Arthritis Rheum. 1995 Nov;38(11):1672-7. doi: 10.1002/art.1780381120. PMID: 7488289.

6. Shiozawa S. HLA-B39 and asymmetric arthritis. Intern Med. 2000 Jan;39(1):8-9. doi: 10.2169/internalmedicine.39.8. PMID: 10674840.

7. Salvarani C, Macchioni P, Cremonesi T, Mantovani W, Battistel B, Rossi F, Capozzoli N, Baricchi R, Portioli I. The cervical spine in patients with psoriatic arthritis: a clinical, radiological and immunogenetic study. Ann Rheum Dis. 1992 Jan;51(1):73-7. doi: 10.1136/ard.51.1.73. PMID: 1540041; PMCID: PMC1004622.

8. Hodinka, L., Gomor, B., Merétey, K., et al. HLA-B27 associated spondyloarthritis in chronic brucellosis. Lancet, 1978, 1, 499

9. Ertem GT, Tanyel E, Tulek N, Ulkar GB, Doganci L. Osteoarticular involvement of brucellosis and HLA-B27 antigen frequency in Turkish patients. Diagnostic Microbiology and Infectious Disease. 2004 Apr;48(4):243-245. D0I: 10.1016/j.diagmicrobio.2003.11.003.

10. Павлюченко А.К. Анкилозирующий спондилоартрит и офтальмопатии // Боль. Суставы. Позвоночник — 2012- Т3, № 7

11. Rolando I, Olarte L, Vilchez G, Lluncor M, Otero L, Paris M, Carrillo C, Gotuzzo E. Ocular manifestations associated with brucellosis: a 26-year experience in Peru. Clin Infect Dis. 2008 May 1; 46(9):1338-45. doi: 10.1086/529442. PMID: 18419433.

12. Касаткина И.Л., Беклемишева Н.Д. Патогенез поражений суставов при бруцеллёзе, Алма-Ата. — 1976. — 232 с.

13. Клинический протокол диагностики и лечение бруцеллеза № 60 от МЗ РК от 29.03.2019 г.

14. Бруцеллез (клиника, диагностика, лечение, организация медицинской помощи): методическое пособие для врачей инфекционистов и врачей общей практики. - Ставрополь, 2013.— 71 с. УДК 616.98.116-002.151:616-07:616-08

๔ Хайдарова Юлдуз Мадихановна ( duzka_0801@mail.ru ), Курманова Гаухар Медеубаевна ( gkurman@mail.ru ), Сейжанова Багжан Бериковна (ms.bagzhan@mail.ru), Курманбекова Молдир Бихитовна (moldir_bahutkuzu@mail.ru ).

Журнал «Современная наука: актуальные проблемы теории и практики»

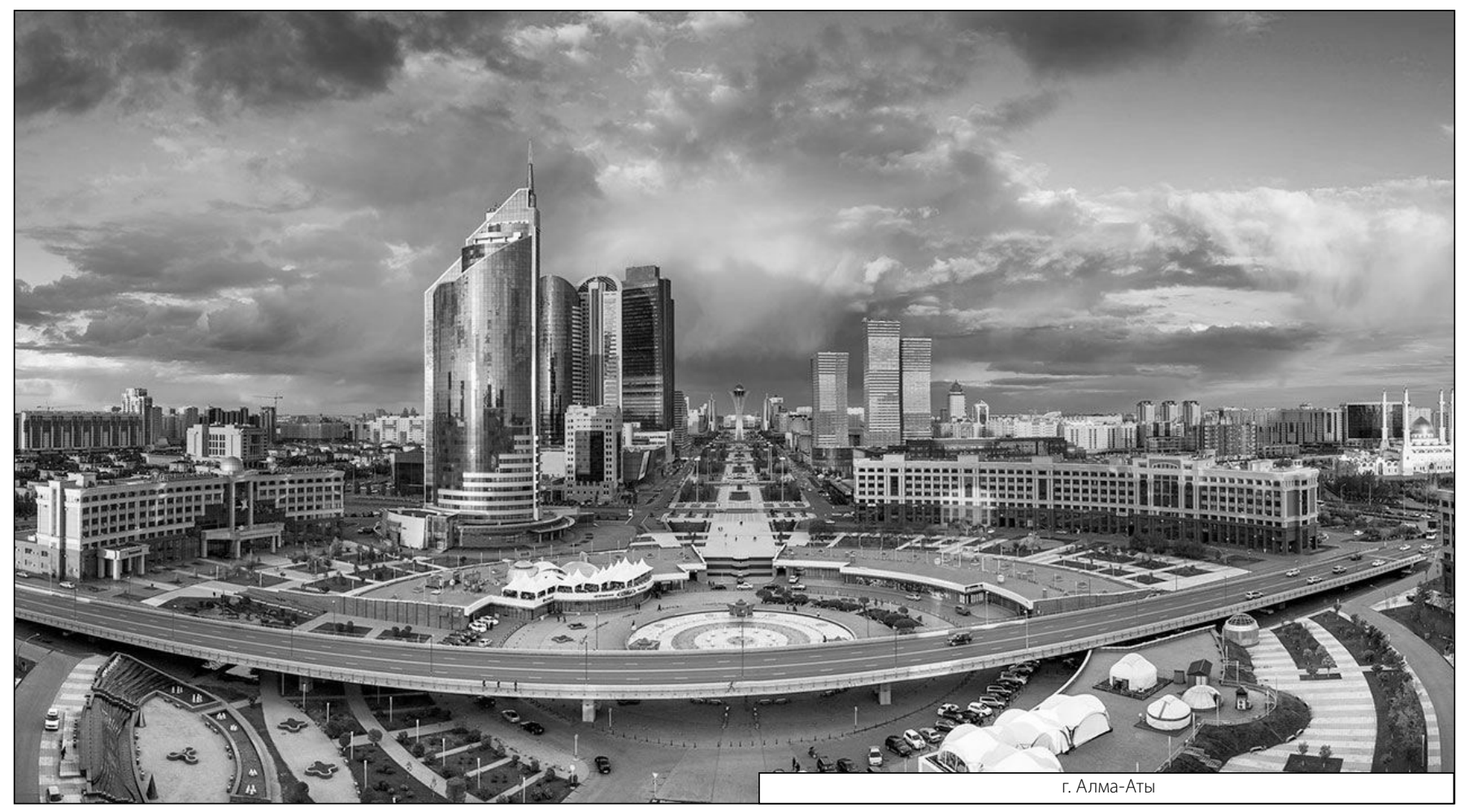

